\title{
The Pervasiveness of Ebola Virus Disease in Africa: Implication for Economy, Ecology and Socio-Religious Dynamics
}

\author{
Nwaoga Chinyere Theresa (Phd), Nche George Christian, F.U Nnadi (Phd) \\ Center For Entrepreneurship And Development Research, University Of Nigeria, Nsukka \\ Department Of Religion and Cultural Studies, University Of Nigeria, Nsukka \\ Department Of Religion and Cultural Studies, University Of Nigeria, Nsukka
}

\begin{abstract}
Within a space of six months from the recent outbreak in March 2014, Ebola virus disease (EVD) has claimed over 2000 lives in Liberia, Guinea, Sierra-Leone and Nigeria. This has indeed shaken Africa to its foundation as several aspects of its life have suffered the adverse effects of the pervasiveness of the EVD. Yet, some of these effects are not necessarily negative. The paper, therefore, critically highlighted some of the implications or effects of EVD in Africa. Using a critical phenomenological method of analysis, it was found that the recent outbreak of EVD in Africa has had a wide range effects that cuts across economic, ecological, socio-religious and cultural aspects of life in the affected countries. Among others, it was recommended that a concerted effort from both governments and citizens would go a long way in containing the spread of the EVD as well as its diverstating effects in the continent.
\end{abstract}

Key Words: Ebola virus disease, ebola-phobia, economic effects, ecological effects, religious effects, social effects.

\section{Introduction}

Africa and the rest of the world are yet to experience a disease that is more pervasive and phenomenal than the Ebola virus disease. In the manner of a wild fire in harmattan, it spreads among people and across cultures, continents and boundaries. It is a severe, often fatal illness with currently no licensed specific treatment or vaccine available for use in people or animal. Direct and unprotected contact with body fluids/secretions of infected persons is considered the principal mode of transmission (PAHO/WHO, 2014). Ebola virus disease has a fatality rate of up to $90 \%$ and has currently resulted in the death of nearly 3000 lives in Liberia, Guinea, Sierra-Leone and Nigeria (WHO, 2014).

This underlines the fear that looms everywhere in the air. Each day and virtually every minute, people consciously avoid body contacts on the streets, in the market, shopping malls, commercial buses, schools, churches, mosques and even among families. Everyone is a suspect including the suspector. Policies have been made by several governments and precautionary and preventive measures taken by individuals in order to nib the virus in the bud. Yet, the outbreak of the ebola virus disease has directly or indirectly had some effects or implications on the economy, ecology, socio-religious, and cultural dynamics of the affected countries in Africa.

The objective of this paper, therefore, is to critically highlight the economic, ecological, socio-religious and cultural elements that have been affected directly or indirectly; negatively or positively by the outbreak of Ebola virus disease as well as the policies and individual preventive measures, including those taken ignorantly, which are aimed at curbing the spread of the virus in Africa. A critical phenomenological method of analysis was adopted to achieve this objective.

\section{The Ebola Virus}

The Ebola virus is also known as Ebola hemorrhagic fever. Ebola virus disease (EVD), Ebola hemorrhagic fever (EHF), or simply Ebola is a disease of humans and other primates caused by an ebolavirus (www.en.wikipedia.org). WebMD has identified Ebola as a rare but deadly virus that causes bleeding inside and outside the body. It added that as the virus spreads through the body; it damages the immune system and organs. In due course, it reduces the levels of blood-clotting cells leading to severe, and uncontrollable bleeding.

The World Health Organisation presents "key facts" about the virus. They are:

- Ebola virus disease (EVD), formerly known as Ebola haemorrhagic fever, is a severe, often fatal illness in humans.

- EVD outbreaks have a case fatality rate of up to $90 \%$.

- EVD outbreaks occur primarily in remote villages in Central and West Africa, near tropical rainforests. 
- The virus is transmitted to people from wild animals and spreads in the human population through human-to-human transmission.

- $\quad$ Fruit bats of the Pteropodidae family are considered to be the natural host of the Ebola virus.

- Severely ill patients require intensive supportive care. No licensed specific treatment or vaccine is available for use in people or animals.

The symptom of Ebola is believed to start two days to three weeks after contracting the virus, with a fever, sore throat, muscle pain and headaches. These will be followed by vomiting, diarrhoea and rash, along with decreased functioning of the liver and kidneys. At this stage, affected people may begin to bleed both within the body and externally. The virus may be transmitted when contact is made with blood or bodily fluids of an infected animal. It should however be noted that the virus is not air-borne. Nevertheless, fruit bats are believed to carry and spread the virus without being affected. When the virus comes in contact with humans, its transmission is likely to spread very fast. It has been observed that "male survivors may be able to transmit the disease via semen for nearly two months. To make the diagnosis, typically other diseases with similar symptoms such as malaria, cholera and other viral hemorrhagic fevers are first excluded. To confirm the diagnosis, blood samples are tested for viral antibodies, viral RNA, or the virus itself." (www.en.wikipedia.org).

WHO identifies several nature of the virus. Genus Ebolavirus is classified to having 1 of 3 members of the Filoviridae family (filovirus), in line with genus Marburgvirus and genus Cuevavirus. Genus Ebolavirus comprises 5 distinct species:

- Bundibugyo ebolavirus (BDBV)

- Zaire ebolavirus (EBOV)

- Reston ebolavirus (RESTV)

- Sudan ebolavirus (SUDV)

- Taï Forest ebolavirus (TAFV).

In their analysis, WHO established that:

BDBV, EBOV, and SUDV have been associated with large EVD outbreaks in Africa, whereas RESTV and TAFV have not. The RESTV species, found in Philippines and the People's Republic of China, can infect humans, but no illness or death in humans from this species has been reported to date. (WHO,2014).

For the virus to be prevented means to reduce rate at which the disease spread from infected animals to humans. In order to do this, proper cross-examination of suspected animals should be done. On the discovery of any infected animal, the online it is suggested that such animals should be killed (if it is still living), and properly disposed. In addition, the proper cooking of meat, and wearing protective clothing when handling meat may also be helpful, as are wearing protective clothing and washing hands when around a person with the disease.

It should be noted that there is no specific treatment for the disease yet. However, efforts are being made to help those who are infected by providing support such as giving "either oral rehydration therapy (slightly sweet and salty water to drink) or intravenous fluids." WHO, WebMD as well as others, identify the disease as having a high risk of death, "killing between $50 \%$ and $90 \%$ of those infected with the virus". (WHO, 2014).

\section{The History of Ebola Virus}

WHO reports that Ebola first appeared in 1976 in two simultaneous outbreaks, in Nzara, Sudan, and in Zaire, Democratic Republic of Congo. The latter, it stated, was in a village situated near the Ebola River, from which the disease takes its name. (WHO, 2014). Mortality rates were $88 \%$ in Zaire and $66 \%$ in Sudan, with 500 cases. In one small village in Zaire, 274 out of 300 people infected in an Ebola outbreak died.(Begley et al, 1995). In 1977 in Zaire, a single case of the virus in isolation was reported. In 1979, Ebola appeared again in Sudan at the sight of the 1976 outbreak. Two other fatal and two other nonfatal cases had been reported. Despite the tremendous effort of experienced and dedicated researchers, Ebola's natural reservoir was never identified. (web.stanford.edu).

The third strain of Ebola, Ebola Reston (EBOR), was first identified in 1989 when infected monkeys were imported into Reston, Virginia, from Mindanao in the Philippines. Fortunately, the few people who were infected with EBOR (seroconverted) never developed Ebola hemorrhagic fever (EHF). In late 1989, Hazelton Research Products' Reston Quarantine Unit in Reston, Virginia suffered a mysterious outbreak of fatal illness (initially diagnosed as Simian hemorrhagic fever virus (SHFV)) among a shipment of crab-eating macaque monkeys imported from the Philippines. Hazelton's veterinary pathologist sent tissue samples from dead animals to the United States Army Medical Research Institute of Infectious Diseases (USAMRIID) at Fort Detrick, Maryland, where a laboratory test known as an ELISA assay showed antibodies to Ebola virus. An electron 
microscopist from USAMRIID discovered filoviruses similar in appearance to Ebola in the tissue samples sent from Hazelton Research Products' Reston Quarantine Unit.

Shortly afterward, a US Army team headquartered at USAMRIID went into action to euthanize the monkeys which had not yet died, bringing those monkeys and those which had already died of the disease to Ft. Detrick for study by the Army's veterinary pathologists and virologists, and eventual disposal under safe conditions. Blood samples were taken from 178 animal handlers during the incident. Of those, six animal handlers eventually seroconverted. However, the handlers did not become ill; the CDC concluded that the virus had a very low pathogenicity to humans.

Other places such as the Philippines and the United States were said to have had no previous cases of Ebola infection. However, from further isolation, researchers concluded it was another strain of Ebola, or a new filovirus of Asian origin, which they named Reston ebolavirus (REBOV) after the location of the incident.

\section{Causes and Means of Spread}

According to the analysis made by Steakley on August 12th, 2014 in Scope, more than 1,800 people in the West African nations of Liberia, Sierra Leone and Guinea have contracted the Ebola virus since March and the death toll has surpassed 1,000. Unfortunately, this has doubled according to the latest figures from the World Health Organization. He went further to state that as the number of cases and death continue to climb, many are concerned about what can be done to curtail the outbreak and the likelihood of it spreading to the United States. It is pertinent to identify the causes and means by which the virus spreads.

$W e b M D$ reports that Ebola is not as contagious as more common viruses like colds, influenza, or measles. It stresses that the virus

...spreads to people by contact with the skin or bodily fluids of an infected animal, like a monkey, chimp, or fruit bat. Then it moves from person to person the same way. Those who care for a sick person or bury someone who has died from the disease often get it. Other ways to get Ebola include touching contaminated needles or surfaces. You can't get Ebola from air, water, or food. A person who has Ebola but has no symptoms can't spread the disease, either.

In a similar but elaborated observation, WHO established that:

Ebola is introduced into the human population through close contact with the blood, secretions, organs or other bodily fluids of infected animals. In Africa, infection has been documented through the handling of infected chimpanzees, gorillas, fruit bats, monkeys, forest antelope and porcupines found ill or dead or in the rainforest. Ebola then spreads in the community through human-to-human transmission, with infection resulting from direct contact (through broken skin or mucous membranes) with the blood, secretions, organs or other bodily fluids of infected people, and indirect contact with environments contaminated with such fluids. Burial ceremonies in which mourners have direct contact with the body of the deceased person can also play a role in the transmission of Ebola. Men who have recovered from the disease can still transmit the virus through their semen for up to 7 weeks after recovery from illness. (WHO, 2014).

In addition, Chris Basler, Ph.D., a virologist specializing in Ebola at the Icahn School of Medicine at Mount Sinai in New York City; and Tim Lahey, M.D., an infectious disease specialist and associate professor of both medicine and microbiology and immunology at Dartmouth's Geisel School of Medicine, during an interview session with Carolyn Kylstra report that:

Even sitting next to a person with Ebola is thought not to be enough to transmit the disease; you need contact with body fluids. If that person sneezes on you, or bleeds on you, or a lot of sweat gets on you, then there is risk of transmission because body fluids have transferred from one person to the other, but Ebola is not airborne. So it requires those visibly obvious things to happen for transmission to occur.

These facts will help to lay off some perceptions of people about the virus.

\section{The Effects of Ebola Virus Disease}

The following are some of the effects of Ebola virus disease in the affected countries especially in West Africa:

\section{Economic Effect}

The economy of the affected countries as well as individuals especially in West Africa has been adversely affected by the outbreak of Ebola virus disease. At the moment, some governments have already earmarked huge sums of money for the provision of special hospitals and medical equipment for the treatment of Ebola patients as well as other logistics that would be necessary for the prevention and containment of the 
Ebola virus disease. For instance, the Nigerian government on $8^{\text {th }}$ August 2014 brought out N1.9billion special intervention fund for the establishment of isolation centres, case management, contact tracing, deployment of additional personnel, screening of borders and the procurement of required items and facilities (Sotubo, 2014). The idea here, is that if not for the outbreak of Ebola virus disease, these moneys would have been available for other purposes like human and infrastructural developments in these countries.

On the other hand, the outbreak of this disease has negatively impacted individual businesses and government-owned business sectors in the affected countries. The sectors mostly affected include aviation, export sub-sector, industries dominated by large scale buying and selling of goods and services, open markets for second-hand clothes, (Udeme, 2014) bush meat business and other businesses within the affected countries. As a result of the fear of Ebola virus disease, people have deserted some of these business sectors while many business men and women now complain of low patronage. According to the interview conducted by the Vanguard Newspaper, Mohammed Tukor, an aviation expert in Murtala Mohammed Airport, Lagos Nigeria, complained of low turn-out of passengers as well as frequent flight cancellation as the major effects on the sector which results in loss of revenue; while many business men and women who for instance, deal in secondhand or family used clothes in Katangura, Lagos and bush meat sellers in Doka village, Kaduna Nigeria complained of unprecedented low patronage (Binniyat, 2014).

Similarly, Freetown, the capital of Sierra Leone is reportedly deserted and business heavily affected. Report has it that in Freetown, all banks limited their hours and are closing at 1pm daily. The thousands of street side vendors, who sell everything from cigarettes and gums to vegetables, are required to close their shops by $6 \mathrm{pm}$ and nightclubs have also been closed by decree (McCordic, 2014). All these have affected the economy of these countries. In fact, according to the Sierra Leone's Agricultural Minister, Joseph Sam Sesay, "the economy of the country has been deflated by $30 \%$ because of Ebola" while the economic effect in Guinea (which is a neighbouring country that is heavily affected by Ebola), according to the World Bank, is expected to fall in GDP growth from $4.5 \%$ to $3.5 \%$.

The outbreak of the Ebola disease has also affected the economy of countries through the death of people especially doctors, nurses and other health workers which reduces the economic manpower of these countries. In fact, it seems that this particularly has a long term economic effect as some of these countries have lost some of their diplomats and medical best brains already to this deadly epidemic.

\section{Ecological Effect}

It has been observed that the cause of the Ebola virus could be in part that human activities have made the delicate ecological balance become unbalanced, adversely effecting the natural state of biodiversity. Due to human mismanagement and consequent destruction of the natural environment, many public health problems have become recurrent. In fact, according to an editorial in Le Palmares, the "mismanagement of public resources which leads to poor management of the environment create opportunistic factors for the birth and spread of epidemics," (Chiahemen, 1995). But be that as it may, the disease seems to be currently affecting all and sundry, including animals.

Wiley (2014), has reported in ScienceDaily that new research in gorillas that were affected by Ebola virus outbreak shows that the disease can influence reproductive potential, immigration and social dynamics, and it highlights the need to develop complex models that integrate all the different impacts of the disease. Ebola has a high mortality among primates. It has been observed that;

Frequent outbreaks of Ebola may have resulted in the deaths of 5,000 gorillas. Outbreaks of Ebola may have been responsible for an $88 \%$ decline in tracking indices of observed chimpanzee populations in 420 square kilometer Lossi Sanctuary between 2002 and 2003. Transmission among chimpanzees through meat consumption constitutes a significant risk factor, while contact between individuals, such as touching dead bodies and grooming, is not. (www.en.wikipedia.org)

In the same vein, Le Gouar et al (2014) has observed that;

Along with the decrease in survival and in reproduction, Ebola outbreak perturbed social dynamics in gorilla populations. During outbreak, transfers of both males and females between social units increased. Some adult females have been observed transferring to nonbreeding groups, which is unusual in non-affected population. Although, six year after outbreak, most of vital rates returned to pre epidemic rate, recovery of the population is slow, especially because no compensatory immigration occurred after outbreak indicating that the neighbouring populations might have been also affected.

This approach requires long-term monitoring of wildlife populations to understand the responses of populations to emerging changes in the environment. 
Domesticated animals are not left out in the study. It is observed that Reston ebolavirus (REBOV) can be transmitted to pigs. This virus was discovered during an outbreak of what at the time was thought to be simian hemorrhagic fever virus (SHFV) in crab-eating macaques in Reston, Virginia (hence the name Reston elabovirus) in 1989. It is also reported that while pigs that have been infected with REBOV tend to show symptoms of the disease, it has been shown that dogs may become infected with EBOV and remain asymptomatic. These dogs are said to be the ones that search for their own food in some parts of Africa. Sometimes they eat infected animals and the corpses of humans. The report has it that "although they remain asymptomatic, a 2005 survey of dogs during an EBOV outbreak found that over $31.8 \%$ showed a seroprevalence for EBOV closest to an outbreak versus $9 \%$ a farther distance away".

From a different perspective, however, the Ebola epidemic has had some ecological effects with respect to biodiversity, conservation and recovery in the affected countries. It has particularly affected the trade in animals and commercial bush meat hunting (Bush-meat is a "colloquial African term" used to describe animals hunted for consumptive and other local livelihood needs. Brown, 2003:2) in these affected countries. This is due to the suggestions or belief by scientists that some animals like chimpanzee, bats, and other bush animals may be serving hosts to the Ebola virus. According to Kevin Olival, a disease ecologist at EcoHealth Alliance in New York City and David Hayman of Massey University in Palmerston North, New Zealand, "fruit bats and other animals like Great apes and antelopes are likely carriers of the Ebola virus" (www.sciencenews.org). Consequently, the previously booming commercial bushmeat hunting as well as trade in some animals has started declining, especially in Africa. People no longer patronize the bushmeat sellers for fear of being infected with the virus through the consumption of such meats. A case in point is in Nigeria, where bushmeat sellers at Doka village Kaduna State have been complaining of low patronage from erstwhile customers, friends and relatives. The Doka bush meat market is the most popular in southern Kaduna, which supplies families, hotels, restaurants and bars in adjoining towns and as far a Plateau and Nasarawa States as well as Abuja with smoked antelopes, primates, pythons, crocodiles, hares, porcupines, wild guinea fowls and even foxes among other animals (Binniyat, 2014). Currently, however, the business is increasingly becoming unattractive as hunters and sellers make little or no money at the end of the day. This is in addition to the stigma some of these bush meat hunters and sellers suffer among their families, relatives and community as people interact with them with suspicion.

The implication of this is that while the bushmeat hunting is becoming discouraging and less-lucrative, the animals are spared in the forests and reserved areas. This leads to biodiversity conservation and recovery especially in Africa "as commercial bushmeat hunting and trade has become a serious threat to biodiversity conservation in Africa". (Brown, 2003; Enuoha and Bisong, 2014).

\section{Religious Effect}

There are several interpretations that have made about the Ebola virus based on religious grounds. Some have been recounted in jocular manner in terms of sociable association whereas others have been taken to the extreme form of involving God.

Online news Godlike Production displayed a headline on $8^{\text {th }}$ June, 2014 " God is angry with Liberia," in which local religious leaders blamed Ebola on 'homosexualism'. This was reportedly followed by a recent recommendation from the Liberian Council of Churches, which said in a statement the previous week that the outbreak has Biblical implications.

Furthermore, and importantly, churches such as the Catholic and Anglican Churches in Nigeria have adopted new methods or procedures for worshipping during Masses as measures to check or contain the spread of the Ebola virus. Some of these procedures include the administration of the Holy Communion on the palm of the Faithful as against the usual act of placing it on the tongue of the recipient, and the stoppage of handshake by worshippers usually done during consecration of the Holy Communion as a sign of peace (www.news24.com).

Other religious effects which though were presented in jocular forms from the title "Ebola and its Spiritual Implication" in airaland Forum include:

1. Pastors now find it difficult to lay 'anointed' hands on their members. (who wan die).

2. We now have security men and medical personnel at the church gate, making a simultaneous check for bombs and Ebola.

3. The sitting arrangements in our churches these days is such that you leave a sit next to your neighbour before you take yours (distant fellowship)

4.People no longer dance forward to drop offerings. Instead, they line up like soldiers, spacing up for a 
wonderful 'match-parade' as armies unto the Lord.

5. Even the ushers fumigate the offerings and wear their own hand gloves before counting God's money.

7. All the ministers and choir members now come to church with personal microphones as its now - "all man for his mic". (www.nairaland.com).

It is worthy to note that the fear of the virus which kills faster than HIV/AIDS can cause a lot of isolations for people even on religious grounds. The extension of courtesy for first timers in the church will be limited to a wave of the hand.

\section{The Socio-cultural Effects}

Some of the socio-cultural elements that have been affected by the outbreak of Ebola virus disease include;

\section{Social relationship}

The spread of Ebola Virus disease and resultant fear and feeling of insecurity has affected social relationships in several ways. In addition to the quick death of loved infected Ebola victims which usually comes with a strong psychological trauma, the fear of being infected has separated homes, friends, colleagues and communities. This fear which could be called "Ebola-phobia" has prevented travels, visitations and close communications among people in several countries and even across countries and continents. Indeed, the impact of this effect can hardly be appreciated until one considers it in relation to man's gregarious nature which always attracts him to his fellow man in a social setting. Nowadays, everyone is suspicious of everyone in every social gathering and setting. This has had negative social effect.

More so, the stigmatization of Ebola victims that is characteristics of virtually every society especially in Africa has negative social effect. For instance, in some, if not all societies, Ebola victims are often treated with hostility and branded as wicked people who deserve to die. Hence, they are dreaded, disowned by relatives and deprived of so many things. This is in addition to the feelings that come with being quarantined and denied freedom of movement. It should however, be noted that while some of these things are justifiable, some are dehumanizing and unacceptable. A case in point is the case of Dannis Akagha, fiancé of the Late Miss Justina Ejelonu who was the the nurse, who contacted and died of the Ebola disease from Mr. Patrick Sawyer at the First Consultant Hospital, Lagos, Nigeria. Dannis Akagha in an interview narrated how he was stigmatized by people in his neighbourhood and by his employer after his late fiancée died of Ebola virus disease.(Amagiya, 2014). Also, there are reported cases of Ebola virus disease survivors who were sacked by their employers and/or sent packing by their landlords in Lagos, Nigeria. (Dachen,2014).

\section{Social Conduct}

The fear of the deadly Ebola virus disease has affected the manner people conduct themselves in several places. Initially, in some cities, it was common to see people or passengers scrambling for limited seats in commercial buses as well as people scrambling for pathways on the streets, in the market which usually make body or physical contact unavailable. It was also common to experience or see scrambles in and out of lecture or seminar halls, which enhances body or physical contacts. These might be considered as acts of social indiscipline.

But nowadays, people are becoming increasingly careful, gentle and disciplined. The fear of being infected by the Ebola Virus Disease has compelled people to always exercise patience while on queues in banks, schools, and on the streets. Everyone is consciously avoiding body or physical contacts with everyone. This has obviously created social order and peace in societies. A case in point is the commercial city of Lagos, Nigeria, which is highly populated and as such had several cases of social disorder as people scramble for limited goods and service. However, since the Ebola epidemic, the city of Lagos is currently enjoying some peace and order as people have been compelled to patiently wait to receive goods and services in turns.

\section{The Culture of Handshake and Hug}

Handshake and hugging are important aspects of social life. They are forms of greetings and have been around in some forms as long as humans have existed. The warm, reassuring tactile touch which they produce is essential for social interaction, social harmony, health, survival and security as well as for communicating feelings (Navarro, 2013).

To some cultures, handshaking and hugging are indispensable ways of greeting, while to others, they are optional and often left at the discretions of people. Yet, to some other cultures, one is preferred to the other 
as in the case of "some cultures especially around the Mediterranean and the Caribbean; where a hug, an air kiss, or an abrazo is preferred to handshake" (Navarro, 2013).

However, in Nigeria, Kenya, Congo, Guinea, Sierra Leone and other African countries, handshaking and hugging are important aspects of culture and forms of greetings that express love, hospitality and acceptability. Unfortunately however, these important cultural elements have been affected by the outbreak of Ebola disease. Nowadays, people consciously avoid handshake and hug for fear of being infected through such physical contacts. While this is advisable and encouraged, it should be noted that it is currently having social effects as conflicts and misunderstandings have ensued between people or friends over one's refusal to shake hands or hug which hitherto have been the usual way of greeting among them.

\section{Suggested Preventive Measures}

The Ebola virus is not peculiar to human beings but to animals also. Therefore, we shall follow the models established by the WHO in suggesting preventive measures to control the spread of EVD in Africa. These models include: Controlling Reston ebolavirus in domestic animals, Reducing the risk of Ebola infection in people, and Controlling infection in health-care settings.

\section{Controlling Reston ebolavirus in domestic animals}

WHO has observed that there is no animal vaccine against RESTV that is available. It therefore advocates for "routine cleaning and disinfection of pig or monkey farms (with sodium hypochlorite or other detergents) to effectively inactivate the virus". It went on to state that if an outbreak is suspected, "the premises should be quarantined immediately. Therefore, the culling of infected animals, with close supervision of burial or incineration of carcasses, may be necessary to reduce the risk of animal-to-human transmission". (WHO, 2014). This should be followed by restricting or banning the movement of animals from infected farms to other areas to reduce the spread of the disease.

In addition, there should be an active animal health surveillance system in order to detect new cases early. This detection will help to send warning to veterinary and public human authorities.

\section{Reducing the risk of Ebola infection in people}

It has been observed that at the initial outbreak of the Ebola virus, there was no effective treatment or a human vaccine. The risk of transmission is increased among those caring for people infected. Recommended measures when caring for those who are infected include isolating them, sterilizing equipment and surfaces, and wearing protective clothing including masks, gloves, gowns, and goggles. If a person with Ebola dies, direct contact with the body of the deceased patient should be avoided. However, because of the widespread of the disease, ZMapp, a monoclonal antibody vaccine was developed. The drug was tasted to be efficient in the treatment of infected animals, but for humans, although some have recovered "the outcome is not considered statistically significant". Favipiravir, an anti-viral drug approved in Japan for stockpiling against influenza pandemics, appears to be useful in a mouse model of Ebola. A 2014 study found that Amiodarone, an ion channel blocker used in the treatment of heart arrhythmias, blocks the entry of Ebola virus into cells in vitro

Nevertheless, the only way to reduce human infection and death is by creating awareness of the risk factors of Ebola infection and the protective measures individuals can take. WHO provides measures which Africa, during EVD outbreaks, should focus on in aiding educational public health messages for risk reduction should focus on. The measures include:

- Reducing the risk of wildlife-to-human transmission from contact with infected fruit bats or monkeys/apes and the consumption of their raw meat. Animals should be handled with gloves and other appropriate protective clothing. Animal products (blood and meat) should be thoroughly cooked before consumption.

- Reducing the risk of human-to-human transmission in the community arising from direct or close contact with infected patients, particularly with their bodily fluids. Close physical contact with Ebola patients should be avoided. Gloves and appropriate personal protective equipment should be worn when taking care of ill patients at home. Regular hand washing is required after visiting patients in hospital, as well as after taking care of patients at home.

- Communities affected by Ebola should inform the population about the nature of the disease and about outbreak containment measures, including burial of the dead. People who have died from Ebola should be promptly and safely buried.

It went on to state that pig farms in Africa can play a role in the amplification of infection because of the presence of fruit bats on these farms. This should involve putting appropriate biosecurity measures in place in order to limit transmission: 
For RESTV, educational public health messages should focus on reducing the risk of pig-tohuman transmission as a result of unsafe animal husbandry and slaughtering practices, and unsafe consumption of fresh blood, raw milk or animal tissue. Gloves and other appropriate protective clothing should be worn when handling sick animals or their tissues and when slaughtering animals. In regions where RESTV has been reported in pigs, all animal products (blood, meat and milk) should be thoroughly cooked before eating.

It has been suggested that "quarantine", also known as enforced isolation, to be usually effective in decreasing spread. Governments often quarantine areas where the disease is occurring or individuals who may be infected.

\section{Controlling Infection in Health-Care Settings}

Human-to-human transmission of the Ebola virus as WHO observed is primarily associated with direct or indirect contact with blood and body fluids. It indicated that transmission to health-care workers has been reported when appropriate infection control measures have not been observed.

Therefore, the preventive measures to be observed in health-care settings will be strictly outlined to health-care workers. WHO outlined that those health-care workers caring for patients with suspected or confirmed Ebola virus should apply, in addition to standard precautions, other infection control measures to avoid any exposure to the patient's blood and body fluids and direct unprotected contact with the possibly contaminated environment. When in close contact (within 1 metre) of patients with EBV, health-care workers should wear face protection (a face shield or a medical mask and goggles), a clean, non-sterile long-sleeved gown, and gloves (sterile gloves for some procedures).

\section{Personal Hygiene}

Since the virus takes its deadly action in a space of days and weeks which would not reach a month, it is not always possible to identify patients with EBV early because initial symptoms may be non-specific. For this reason, WHO establishes that it is important that health-care workers apply standard precautions consistently with all patients - regardless of their diagnosis - in all work practices at all times. These include basic hand hygiene, respiratory hygiene, and the use of personal protective equipment (according to the risk of splashes or other contact with infected materials), safe injection practices and safe burial practices.

In addition, people should ensure that they did not touch dead bodies. Traditional burial rituals, especially those requiring washing or embalming of bodies, should be discouraged or modified People should keep away from dead animals, and adequately bury them or report several of such cases to health-care workers. Individuals and families should ensure that they properly cook the meat before consuming it. Above all, people are encouraged not to put their fingers in the nose, rub it against the eye, but to wash their hands from time to time, since handshake is meant to come, with soap as the virus does not survive from such activities.

\section{Recommendations}

In addition to the above, the following specific recommendations should be put into serious consideration in order to cushion the effects of Ebola virus in Africa:

1. There should be a concerted effort or corporation from both the governments and citizens of the affected countries as well as other neighbouring countries, in the fight against the outbreak of Ebola virus disease in Africa.

2. Funds or financial aids should be made available for the heavily affected countries such as Liberia, Sierra-leone and Guinea, to effectively combat the spread of this virus. To this effect, the international organisations, philanthropists and more developed countries should assist in this regard.

3. There should be consistent and effective enlightenment programs or workshops organized by the governments, NGOs and other stakeholders to educate people on the nature of the EVD.

4. Also, more intensive research should be done by scientists to ascertain more accurately, the actual source of the ebola virus disease as well as its effect on biodiversity. This will help in defining or streamlining the role people can play in preventing the spread of the virus.

\section{Conclusion}

So far, the paper has highlighted some of the effects of the outbreak of Ebola virus disease in West Africa. These effects cut across the economic, ecological, socio-religious and cultural dynamics in Africa. Whereas some of these effects were said to be negative, some are positive. However, these effects are predominantly negative especially those that are related to the economy and ecology (with respect to the possible impact on the reproductive ability in some animals such as gorillas) of the affected countries in Africa. Be that as it may, the main task of the paper was to highlight these effects and suggest possible ways of 
cushioning them, while the fight against the spread of EVD last. Therefore, if the above recommendations in addition to the suggestive preventive measures as provided by the World Health Organization (WHO), are followed strictly, the war against the spread of EVD and its effects shall assuredly yield desired results.

\section{References}

[1]. Amagiya, F (2014) How I Survived Ebola-Dennis Akagha (www.vanguardngr.com) Assessed on $20^{\text {th }}$ September 2014.

[2]. Begley, S, Alden, C, Christopher, D, and Dana, L, (1995) Commandos of Viral Combat, Newsweek (May 22, 1995$)$, 50.

[3]. Binniyat, L (2014) Rage of Kaduna Bush Meat Sellers: “Why has Ebola not killed us?" (www.vanguarngr.com) Assessed on 30 August 2014.

[4]. Brown (2003) Is the best the enemy of the good? Livelihoods Perspective on Bushmeat Harvesting and Trade: Some Issues and Challenges. Paper presented at the International Conference on Rural Livelihoods, Forests and Biodiversity, 19-23 May 2003, Bonn, Germany.

[5]. Brown (2003) Is the best the enemy of the good? Livelihoods Perspective on Bushmeat Harvesting and Trade: Some Issues and Challenges. Paper presented at the International Conference on Rural Livelihoods, Forests and Biodiversity, 19-23 May 2003, Bonn, Germany.

[6]. Chiahemen, J (1995) Virus Refocuses World Attention on Zaire. Reuters North American Wire(May 14, 1995).

[7]. Dachen, I (2014) Ebola Virus Disease Survivors Thrown out of Jobs and Houses in Lagos. (www.pulse.com) Assessed on 28 September 2014.

[8]. Ebola and the Spiritual Implications (www.nairaland.com). Assessed on $15^{\text {th }}$ September 2014.

[9]. Ebola virus disease. (www.en.wikipedia.org) Assessed on $10^{\text {th }}$ September 2014

[10]. Enuoh, O.O and Bisong, F. E (2014) Biodiversity Conservation and Commercial Bushmeat Hunting Challenges in African Parks and Protected Areas: A Critical Review and Synthesis of the Literature. Research on Humanities and Social Sciences (vol.4) No.18.pp: 31-49.

[11]. Fauquet, C.M. (2005). Virus taxonomy classification and nomenclature of virus: $8^{\text {th }}$ report of the International Committee on Taxonomy of Viruses. Oxford: Elsevier/Academic Press. p. 648.

[12]. Feldmann, H and Geisbert, T.W (2011). Ebola haemorrhagic fever. The Lancet 377 (9768): 849-862.

[13]. Gatherer D (2014). The 2014 Ebola virus disease outbreak in West Africa. J. Gen. Virol. 95 (Pt 8): $1619-1624$.

[14]. Hamilton, R (2014). Ebola Crisis: The Economic Impact (www.bbc.com) Assessed on 30 ${ }^{\text {th }}$ august, 2014.

[15]. Hesman, S. T (2014) Animal Source of Ebola outbreak Eludes scientists (www.sciecenews.org) Assessed on $12^{\text {th }}$ August 2014.

[16]. Klenk, H (1999). Marburg and Ebola Viruses: Current Topics in Microbiology and Immunology. Berlin: Springer-Verlag Telos.

[17]. Kuhn, J. H. (2008). Filovirus: A Compendium of 40 years of Epidemiological, Clinical and Labouratory Studies. Archives of Virology Supplement, vol. 20 (Limited preview). Vienna: SpringerWienNewYork.

[18]. Le Gouar P, Genton C, Pierre A, Cristescu R, et al (2014). How Ebola impacts social dynamics in gorillas: A Multistate Modelling approach. Journal of Animal Ecology.

[19]. Mccordic, C (2014). Ebola Frontline: The Economic Impact of Ebola is Making Freetown a Ghost Town (www.newsweek.com) Assessed on $30^{\text {th }}$ august, 2014.

[20]. Navarro, J (2013). The Art of handshaking (www.psychologytoday.com) Assessed on $5^{\text {th }}$ Septmeber, 2014.

[21]. Pan American Health Organization and World Health Organisation (PAHO/WHO) (2014) Ebola Virus Disease (EVD) Implications of Introduction in the Americas. Corrigendum ${ }^{1}$ (13 August 2014) pp: 1-14.

[22]. Pattyn, S. R. (1978). Ebola Virus Haemorrhagic Fever (1 st ed.). Amsterdam: Elsevier/North-Holland Biomedical Press.

[23]. Pringle, C. R. (2005). "Order Mononegavirales". In Fauquet, C. M.,Mayo, M. A., Maniloff, J., Desselberger, U., Ball, L. A. Virus Taxonomy - Eighth Report of the International Committee on Taxonomy of Viruses. San Diego, US: Elsevier/Academic Press. pp. 609-614.

[24]. Ryabchikova, E. I. and Price, B. B. (2004). Ebola and Marburg Viruses: A View of Infection Using Electron Microscopy. Columbus, Ohio: Battelle Press.

[25]. Sotubo, J (2014) Controversy arises over N1.9Billion Ebola Fund (www.pulse.ng). Assessed on $4^{\text {th }}$ September, 2014.

[26]. Starkey, J (2014). 90 Killed as Fruit Bats Spread Ebola virus across West Africa. The Times. Assessed on $10^{\text {th }}$ September 2014.

[27]. TED case study: Ebola and Trade-American University (www1.american.edu) Assessed on $12^{\text {th }}$ August 2014.

[28]. Udeme, C (2014) Ebola Hits the Economy (www.vanguardngr.com). Assessed on $30^{\text {th }}$ august, 2014.

[29]. Wiley. (2014). Ebola has profound effects on wildlife population dynamics. ScienceDaily, 18 August 2014. (www.sciencedaily.com). Assessed on $10^{\text {th }}$ September 2014.

[30]. WHO (2014) Ebola virus disease Fact sheet $N^{\circ} 103$. (www.who.int) Assessed on $10^{\text {th }}$ September 2014.

[31]. WHO (2014) Ebola virus disease, West Africa - update 28 August 2014. (www.who.int) Assessed on $10^{\text {th }}$ September 2014.

[32]. WHO (2014) Ebola virus disease update, West Africa - update 28 August 2014: Epidemic \& Pandemic Alert and Response (EPR) Outbreak News. (www.who.int) Assessed on $10^{\text {th }}$ September 2014.

[33]. WHO (2014) Ebola Virus Disease (EVD) outbreak in West Africa (www.who.int) Assessed on $10^{\text {th }}$ September 2014. 